\title{
Gorresponderte.
}

\section{ANTI-CHOLERA INOCULATION.}

To the Editor, " Englishman."

Sir,-Some, at least, of the Municipal Commissioners of Calcutta have been awaiting, with much curiosity, the longdeferred motion that the Municipality should cease to spend money on inoculation against cholera. Dr. Sanders stands in so singular a position, unique (I think) among men of any note, in his positive hostility to this work, that we have been wondering what could be the causes of this antagonism.

Up to Thursday last his reticence, and that of such persons as share his views, have been in very marked contrast to the openness and readiness shewn by Professor Haffkine and others, not only to investigate facts, but also to make public and intelligible the results of experience. Questions, minute and theoretical (such as could scarcely be addressed with propriety to the Chairman of a Municipality), have been put to Mr. Williams, and these have been answered with great fulness and candour. And the Health Officer has been good enough to condense for us into a moderate compass, the accumulated experience of those who have done the work On the other side there has been not a word.

In these circumstances it was something gained on Thursday, the 2 nd instant, when, although his motion was once more postponed, Dr. Sanders at length told us that he had three objections to offer, viz.

I. That our expenditure of Municipal money on this inoculation is illegal;

II. That the inoculation is useless :

III. That it is dancerous.

I will take each of these propositions in turn

I. The expenditure is illegal.-The Municipal Commissioners have been giving a moderate grant for many months. Among their number are numerous lawyers, barristers, attorneys and pleaders. Yet it is from none of these that this objection comes, but from a layman, who is hold enough to suggest that, at his instance and without reasons, the Commissioners should stultify themselves by declaring their own long-continued proceedings to be illegal. How does the case stand? The relevant law, so far as I know it, is to be found in sections 36 and 37 of the Municipal Act. The former of these sections (the portions relating to other matters being omitted) runs:- "The purposes expressly authorized by this Act shall be held to include the objects connected with the public safety, health, instruction and convenience hereinafter specified, that is to say :-

(3) Defraying the cost of the construction and maintenance of hospitals and of charges of vaccination.

"And generally all objects connected with the public safety, health and convenience." The relevant passages of section

It shall be the duty of the Commissioners, and they are hereby required to-

(5) Make adequate and suitable provision for each of the following matters :-

$(p)$ "The preventing and checking the spread of dangerous diseases." Other sections (e.g., section 321) shew that cholera is a "dangerous disease" within the meaning of the Act.

These, then, are the words of the law : they are very wide, and appear to me to be equally clear.

II. The inoculation is useless. - Dr. Sanders has undertaken the difficult task of proving a negative. But this should not be pressed; I will at once say that it is for those who wish to spend the Municipal money to shew that the system is, or is likely to be, useful. The full and careful report of the Health Officer places this beyond doubt.

\section{Proportion of deaths} among inoculated. 1.93 per cent. 0.37 $6 \cdot 25$,"

Nil.

$2 \cdot 04$ per cent

Proportion of deaths
among uninoculated.
$3: 59$ per cent.
8.37 ",
$9.66 \quad$ ",
$2 \cdot 78 \quad$ ",
$3.94 \quad$ ",
$22.44 \quad$ "

The above comparisons, the figures in the respective cases being placed opposite each other which shew some only of the instances given in the report, tell their own story. And hard-headed practical people are now shewing what they think of the system. Let reference be made to the East Indian Tea Association, the Bengal-Nagpur Railway, the Bengal Paper Mills, the Agents and Managers of many Tea Gardens, the Captains and Agents of ships.

III. The inoculation is dangerous. - This is the point in which Dr. Sanders must help us since the burden of proof rests on him. He is not merely a Municipal Commissioner but he is a distinguished member of the Indian Medical Service; and when such a person commits himself to a positive assertion of so great importance (which he would not lightly do) the public have a right to ask him for information as clear and definite as that which is given by Professor Haffkine and Dr. Simpson. If the system can be proved to be dangerous, let this be done without loss of time, so that we may compare the dangers with the apparent advantages, and judge which preponderate. This is the concern, not merely of the Municipality, but also of the Government and of the people. For the Government has of late been largely interesting itself in the system and deputing one officer after another to attain a practical knowledge of it. All this should be stopped if that system entails excessive risks.

Where is the danger? What is its origin? What are its causes? What is it precisely that is to be feared, and why? These and other questions are such as Dr. Sanders, I venture to think, is bound to answer at once if he expects to be taken seriously. Those who are experts in the practice of inoculation, tell us that the inoculated suffer temporary inconvenience, but that there is no danger whatever.

July $9 t h$.

A MUNICIPAL COMMISSIONER.

II.

Sir,-Just one word, in reply to "A Municipal Commissioner's" letter in your issue of the 11th.

I am not writing to oppose M. Haffkine's system of inoculation. That is unnecessary since the appearance of the May number of the "Annales de l'Institute Pasteur." I write because I object to the following sentence in that letter : - "Dr. Sanders stands in so singular a position, unique (I think) among men of any note in his positive hostility to this work that we have been wondering what could be the causes of this antagonism."

The cause of not only Dr. Sanders' antagonism, but of a passive antagonism in all I. M. S. physicians of experience, if not "of note", is that they have long seen that $M$ Haffkine's vaccinations are practically useless. The as yet doubtful degree of success attained by him, by no means warrants the trouble required in applying his method to practice here, and M. Haffkine himself carried away in his enthusiasm, has overlooked the work of Ransom and Behring last year.

July 12 th.

JUSTE CIEL !

III.

SIR,-I do not know who your correspondent who adopts the pseudonym of "Juste Ciel" may be, but I beg to take exception to his ridiculous assertion that " the cause of not only Dr. Sanders' antagonism, but of a passive antagonism in all I. M. S. physicians of experience, if not, 'of note' is that they have long seen that M. Haffkine's vaccinations are practically useless." Such an assertion, if made seriously should be at least capable of support by proof, which $I$ venture to think it is not. So far as my own experience goes, those officers of the Indian Medical Service who have the requisite knowledge of M. Haffkine's methods and results from personal observation and work are, one and all, convinced of the great utility of the anti-choleraic vaccination as a preventive measure. Among others of this category are Surgeon-Lieutenant-Colonel Macrae, Surgeon-Captain Harold Brown, Surgeon-Captain Hare, Surgeon-Lieutenant-Colonel Comins, and Surgeon-Lieutenant-Colonel Crombie, all of whom have either officially or unofficially pronounced in favour of the anti-choleraic vaccination. How then can "Juste Ciel " make such an unfounded assertion!

To say that there is a passive antagonism in all I. M. S. physicians of experience is a mis-statement which in view of the importance which may possibly be attached to it by those ignorant of the real facts, cannot be allowed to pass unchallenged.

That there was at first a cautious avoidance of blind acquiescence in the methods advocated by M. Haffkine is no doubt true, but this caution is thoroughly in consonance with the seientific attitude towards any newly advanced method ; and to assert as "Juste Ciel" does that all Indian Medical Service physicians of experience are adopting an attitude of "passive antagonism" is an attempt to attach to the service a stigma of ignorant prejudice, which many will, like myself, resent and repudiate.

"Juste Ciel" goes on to speak of the "doubtful degree of success attained by M. Haftkine." Surely he must be unaware of the published results of $\mathbf{M}$. Haffkine's work. The fact is that the degree of success already attained is several times higher than that obtained by the use of serum in the curative treatment of diphtheria, while it has the additional advantage of being preventive rather than curative.

In the elaboration of the serum-treatment of diphtheria vast sums of money were spent: in Paris alone no fewer than two million francs $(£ 80,000)$ were expended. In comparison with this does not the trouble so far taken to advance the anti-choleraic vaccination sink into insignificance? 
" Juste Ciel" says that " the trouble required in applying II. Haffkine's methods to practice here is not warranted." Undoubtedly, under existing conditions, the trouble to the operator is enormous : and it should be remembered that for over three years M. Haffkine undertook this labour almost single-handed. The trouble, however, is capable of being minimised by organization, the lines of which will no doubt be found out by experience, while a process which affords so high a degree of protection aqainst cholera is worth any amount of trouble. "Juste Ciel's" allusion to the May number of the "Annales de l'Institute (sic) Pasteur," and to Ransom and Behring is an attempt to depreciate the observations of years, and the results of careful experiment which have convinced those under whose superintendence they were made, jail officers, medical officers of coolies in tea gardens, railways and elsewhere, upon the statement of a magazine article dealing with laboratory experiments only; such an attempt is not only unpractical, it is highly unfair.

It is, to say the least, ungenerous to use the columns of a daily paper to anonymously attack a man who may justly claim to have his work judged, not by the general public, who cannot in the nature of things know the facts, and may be misled by such irresponsible critics as "Juste Ciel," but by those of the medical profession who have studied the subject and are competent to judge.

Apologising for the length of this letter.

GEORGE RANKING, M.D.,

$$
\text { 17, Elysium Row, July 15th. }
$$

\section{IV.}

SIR,-After the appearance of Surgeon-Lieutenant-Colonel Ranking's letter, I at once withdraw the "assertion" I made. I am sure that none but myself can be opposed to Haffkine's system now. Speaking for myself then, I repeat, that " the as yet doubtful degree of success obtained by him," (Mr. Haffkine) "by no means warrants the trouble required in applying his method to practice here." Dr. Ranking states "the fact is that the degree of success already attained is several times higher than that obtained by the use of serum in the curative treatment of diphtheria, while it has the additional advantage of being preventive rather than curative." Now, that statement is not supported by figures, and if Dr. Ranking had produced his figures, I would have asked:What degree of scientific value are we able to place upon each? Nothing is called diphtheria to-day, where the KlebsLoffler bacillus is not seen. I ask Dr. Ranking now, if we ever attained success in a " new treatment,"-in the present day meaning of that term,-without laboratory experiments, and if such laboratory experiments were not made before the treatment, as a rule? Is not cholera one of the diseases that have come to be known as "toxi-microbiennes" and in that alone, is it not quite different from the "choleraic peritonitis" of guinea-pigs? Knowing this, and with Behring Metchnikoff and Roux now, so clearly showing us another way, what right have we to waste our resources as we now propose to do?

July 21st.

JUSTE CIEL.

\section{V.}

SIR,-I feel constrained to furnish the figures asked for by "Juste Ciel" lest my abstaining from doing so should be misconstrued by the general public, and thus an injustice be done to the cause of cholera preventive inoculation; but in doing so I must ask "Juste Ciel" to regard this as the last word on the subject, unless he is a medical man, and will kindly submit such arcuments as may seem to him to support his position to the columns of a medical paper where the question can more advantageously be discussed.

The case of diphtheria stands thus :-

The reduction of mortality by the antitoxic serum has been reported by Roux in his communication to the International Medical Congress at Buda-Pesth in 1894 to be from fifty per cent. to twenty-six per cent., the mortality thus having been reduced, roughly speaking, twice.

Professor Virchow, commenting upon the result obtained in Berlin and describing them as "brilliant," gives the reduction of mortality from $37 \cdot 63$ per cent. to $11 \cdot 2$ per cent. which is a reduction of roughly three and-a-half times.

The Medical Superintendent of the Metropolitan Asylums Board in London, reports a reduction of mortality from $29 \cdot 6$ per cent. to $22 \cdot 5$ per cent., or roughly one and a third times.

The Board of Health in New York give their results a showing a reduction of mortality from $34 \cdot 66$ per cent. to $19 \cdot 43$ per cent., or roughly one and-a-half times (slightly over this proportion).

We thus see that the average reduction of mortality in diphtheria by the use of antitoxic serum is roughly speaking twice, that is to say, of every two otherwise fatal cases one is eured.
Now in the case of the preventive system of inoculations for cholera the figures are as follow :-

When it is applied after an epidemic has actually broken out there is observed :

(a.) A reduction of mortality amounting to twice. Authority, Surgeon-Lieutenant-Colonel Macrae, Gya Jail.

(b.) A reduction of mortality amounting to four times. Authority, Surgeon-Captain Harold Brown, Durbhanga Jail. (c.) A reduction of mortality amounting to seven and-ahalf times. Authority, Surgeon-Major Silcock, Civil Surgeon, Bilaspur Coolie Camp.

(d.) A reduction of mortality amounting to nine and-aquarter times. Authority, Surgeon-Captain Hare, Camp of the Assam-Burma Railway.

The average of the above shows that the reduction of mortality was $5 \cdot 7$ times, or in other words, that whereas among those persons not protected by inoculation six would die, among those protected by inoculation only one would die.

Even this shows a sufficient reason for the statement made by me in my letter as to the comparative results obtained in these two diseases. But this is not the whole case.

In the case of the curative treatment of diphtheria by serum it is acknowledged that the effects of the serum pass off in a few days, whereas in the case of preventive inoculation for cholera it is shown conclusively that after combating the dan. gers attendant upon the existing epidemic, the inoculation leaves a protective effect for a considerable period.

The degree of this protection is shown by the recent report of the Health Officer of Calcutta to be, during the year following the first four days of treatment, over 22 times greater than that possessed by non inoculated persons: in other words, whereas 22 non-inoculated persons die from cholera, inoculated members of these same families would have only one death.

It is difficult to see what conclusion can be arrived at from these figures other than that put forward in my former letter.

$$
\text { July } 21 \text { st. }
$$
GEORGE RANKING.

\section{"The Flummery of Science."}

* * * Make clear to us your grounds of opposition ; give us reasons, if you can, why failure is to be expected; explain away in detail if you can, the long tale of alleged successes; if you regard the system as dangerous, tell us fully and clearly why you so regard it.

\section{VI.}

SIR,-“"A Municipal Commissioner" must excuse me ; he is far too exacting. In the tropics, I fear, but few of us have the cerebral energy he requires and, moreover, * * "La médecine n'est pas née pour charmer les loisirs du savant, ni pour exercer agréablement l'esprit de discussion, elle a un but plus utile et plus élevé."

July 24th.

JUSTE CIEL.

\section{VII.}

SIR,-I perceive that "Juste Ciel" has collapsed, and we are not to have "Heaven's light," as our guide! Like the naughty boy in Punch, who chalked up "No Popery" and ran away, he has written up " No Inoculation," and made his escape. I will ask you and your readers to say whether this is the proper way of dealing with an important subject.

Dr. Sanders honoured me yesterday by mentioning my humble contributions to your paper : he has satisfied himself that the writer is Dr. Simpson, and that I am a mere " nominis umbra." I never like to contradict flatly, and will, therefore, be content to say that $I$ doubt if he is right. My object in assuming a " nom de plume" was to divest the discussion as far as I could of personal consideration. If what was written is sound, let it stand ; if is not, let it fall. Dr. Sanders' attempt to penetrate my disguise justifies me.

I will not tire your readers with further controversy for some time to come. Meanwhile the work is to continue here and Dr. Haffkine, I see, has goneto Poona.

\section{July $27 t h$. \\ A MUNICIPAL COMMISSIONER.}

P. S.-I wish to say that I do not approve of Dr. Simpson's proposal to put the establishment on a permanent footing. We do not know enough to bind ourselves in this way, and all that it is reasonable to do is to continue our temporary measures and add to our knowledge of facts.

VIII.

SIR,-I am glad to find "Commissioner" is not the man I thought he was. From his own indiscretion $I$ know now who he is. I wish he would not use the great influence he rightly possesses to ask for votes. I have asked no one for his vote. I asked no one to second my proposal. If he can prove this 
point I shall be glad. If not, I hope the money which we find we can spend may be used in a more practical manner to prevent cholera. All new treatment has three stages : 1st-It cures everything. 2nd-It is doubtful. 3rd-It cures nothing. Let him remember the cure of consumption : and will he read the article in the current number of the Contemporary Review about the modern treatment of diphtheria?

July $28 t h$.

R. C. SANDERS.

IX.

SIR,-I did not intend to trouble you again so soon, but Dr. Sanders has "drawn" me, and I can no more refuse to come out than an iron filing to follow the magnet, or the mollusk of the coster's barrow to yield to the extracting pin.

My "indiscretion" has revealed me! Had the debate continued I should have revealed myself. But Dr. Sanders is mistaken in thinking that I have tried to influence votes in any illegitimate way. I do not remember having asked any Commissioner for his vote, though I have spoken to more than one on the subject, and have explained what I thought was our right course. I should be extremely sorry to gain a single vote through mere influence, even though I did possess all the power which Dr. Sanders attributes to me.

Dr. Sanders says - "All new treatment has three stages ; 1st-It cures everything. 2nd-It is doubtful. 3rd--It cures nothing," The moral of this is that there can be no such thing as new treatment. We know all that is to be known, and do all that is to be done! Science and art are alike hidebound! I have frequently heard people ask why Dr. Sanders is so hostile to further experiments on inoculation against cholera. Thiese utterances supply the reason. A man who holds such views as to " all new treatment" cannot be expected to sympathise with attempts at progress.

It is right for me to say that no one, so far as I am aware, has ever claimed for the inoculation that "it cures everything." It is only those who oppose it actively who complain that it does not perform impossibilities. Professor Haffkine himself takes far lower ground. He says that our knowledge, both as to methods and as to results, is as yet very incomplete; but the statistics of past operations are so favourable as to encourage us to proceed. This is not the language of a wild enthusiast, but of a calm and cautious man of science. The present writer has not the slightest personal interest to gain by advocating the continuance of the work for the present. He is just as averse to wasting municipal money as any other taxpayer. But he is satisfied that success would be of enormous benefit to the public, and that there is a fair promise of success.

July $30 t h$.

\section{A MUNICIPAL COMMISSIONER.}

THE TEST FOR THE CHOLERA MICROBE.

Sir,-A correspondent, signing himself "Vox FAucibus HESIT," publishes a letter in the current number of the Indian Medical Gazette, in which he quotes the statements of certain European authorities to the effect, that the cholera microbe rapidly dies when placed in certain specimens of water of European origin. Your correspondent makes the rash assumption that these statements hold good of the cholera microbe in Indian water, and laments that he is officially obliged to send such specimens of water to be tested as to the presence of the cholera microbe, as he appears to think it probable that the cholera microbes would have died out en route. Your correspondent further states that he has sent water for examination on two occasions, and in each case, received a report to the effeet that cholera microbes were detected. May I ask your correspondent whether the report stated that the cholera microbes were found alive? If not, the reasoning of your correspondent would appear to lose its cogency, for it is at least possible that the microbes were found dead by means of the hand centrifuge. Such an eventuality is the more probable if the water had been taken from a well previously treated with potassium permanganate.

AGRA, 24th July.

E. H. HANKIN.

\section{THE BEST WAY OF VACCINATING.}

SIR,-The article by Surgeon-Captain Moir, in your last issue, tempts me to write here.

With him I believe we are wrong in not re-vaccinating more actively in jails and everywhere else ; but it has appeared to me that where one man vaccinates most successfully, another too frequently fails, even with a faultless lymph.

Before reading Dr. Moir's article I had been attributing my own success among prisoners to the method deseribed below. Now, however, the only advantage it would appear to have is, that in children it more often gives us a typical vesicle and prevents interference with the lymph's absorption by the bleeding of scratches in a crying child.
In a French Journal I recently saw an article " Le meilleur procédé de vaccination" by a Dr. G. Jroisenne. He states first, that any flow of blood in the operation is against success, and that scarifications, though preferable to punctures, too often give rise to pustules, unnecessarily large, confluent or multiple. He then goes on to say * * * "Here, in all its details, is my simple operation. After washing with soap, I disinfect with alcohol (spirits of wine), rarely with ether, because of the cold, which makes young children cry. When the skin is perfectly dry, I stretch it with the left hand and then with a disinfected instrument-lancet, bistoury, pocket-knife, but preferably a tenotome with its point blunted,-I scrape over a skin space of at most three millimetres square so as only to remove the epidermis and lay bare the true skin without touching any of the vessels. This is very easy to do, and the amount of scraping required depends on the individual's skin. It is always well to choose a smooth part without hypertrophied glands and without hairs. In this way, we reach a surface rich in lymphatics, and which absorbs most rapidly. The lymph applied is taken up almost at once, and the surface becomes soon dry. In reality the lymph does not dry there, it disappears within the living tissues."

\section{(Sd.) VACCINATOR.}

\section{ANTI-SYPHILITIC SERUM.}

\section{To The Editor, "Indian M edical Gazette."}

DeAR SrR,-Since August of last year we have prepared liquid-Anti Syphilitic Serum for purposes of clinical trial, and are now issuing it in the form of dried scales, possessing the full potency of the liquid serum.

In the accompanying pamphlet will be found a short historical sketch of this method of treating syphilis, which is still under trial, and the account of a case recently reported by an English observer.

The prominence in medical treatment given to AntiDiphtheritic Serum has somewhat overshadowed several departures in serotherapy of scarcely less importance. Not the least interesting of these is the introduction of AntiSyphilitic Serum.

In an able résumé of this subject, Dr. Paul Raymond remarks that, valuable as mercury may be in syphilis, it is certain that we possess in it an agent which, although curative, does not confer immunity against relapse. It was, therefore, certain that attempts would be made to treat syphilis by serotherapy. It is not illogical to consider that the microbe of syphilis like that of other infectious diseases, secretes toxines which can confer immunity. And it may be asked if animals are not refractory to syphilis because there are to be found in their blood chemical or other substances by contact with which the microbes of syphilis or their products are destroyed. From this it is a natural step to apply to syphilis the views which, in other affections, have been crowned with success.

It was by injections of animal serum that a commencement was made. Researches in this direction were made in 1891, in the wards of Dr. Feulard, at the St. Louis Hospital. The results of these experiments have been included in M. Fournier's recent work on the treatment of syhilis. It may be stated generally that these injections seemed to produce a favourable effect. MM. Feulard and Fournier agree that they at least contributed towards improving the general health. They both believe that the treatment may render great service when nutrition needs improvement. They employ the serum of the dog and horse, one centigramme every two days.

Tommasoli has tried this method, and his results were published in 1892. He used the serum of the sheep and calf in larger doses than those employed by Fournier or Feulard. He injected from two to eight cubic centimetres daily but not for more than 14 injections. The results were satisfactory, syphilitic manifestations having in some cases disappeared at the sixth injection. Dr. Istomanoff has lately carried out Tommasoli's method, and states that secondary symptoms have completely disappeared after 15 injections of two to six cubic centimetres a day. These authors do not pretend to have solved the question of the cure of the disease nor of immunity against a new infection. At the late congress at Rome, Tommasoli stated that some of his patients, who seemed at first cured, had had relapses.

M. Kollmann, who was the first to apply this method to syphilis, employed the serum of the calf, sheep, dog and rabbit, with negative results. The injections were made on the appearance of secondary manifestations, but in no case produced recognisable favourable influence upon the disease. It is important to note that Kollmann's patients were kept under observation for more than a year. At the Congress of Nuremburg, in 1893, he returned to the subject. His experiments were made on 18 patients, and, in spite of very large doses of serum, the results were discouraging. In some 